\title{
Volume Balance in Chronic Kidney Disease: Evaluation Methodologies and Innovation Opportunities
}

\author{
Edoardo La Porta ${ }^{a} b$ Luca Lanino ${ }^{b}$ Marta Calatroni $^{c}$ Elena Caramella ${ }^{d}$ \\ Alessandro Avella ${ }^{e}$ Caroline Quinn ${ }^{f}$ Alessandro Faragli ${ }^{g}, h, i, j \quad$ Luca Estienne ${ }^{k}$ \\ Alessio Alognah,i,j Pasquale Espositol \\ ${ }^{a}$ Department of Cardionephrology, Istituto Clinico Di Alta Specialità (ICLAS), Rapallo, Italy; ${ }^{b}$ Department of Internal \\ Medicine (DIMI), University of Genoa, Genoa, Italy; 'Division of Nephrology, Humanitas Clinical and Research \\ Center, Milan, Italy; ${ }^{\mathrm{d} D i v i s i o n}$ of Nephrology and Dialysis, Ospedale Sant'Anna, San Fermo della Battaglia, Como, \\ Italy; ${ }^{~}$ Division of Nephrology and Dialysis, Ospedale di Circolo e Fondazione Macchi, Varese, Italy; ${ }^{\text {fDepartment }}$ \\ of Biological Sciences, Rensselaer Polytechnic Institute, Troy, NY, USA; ${ }^{9}$ Department of Internal Medicine and \\ Cardiology, Deutsches Herzzentrum Berlin, Berlin, Germany; ${ }^{h}$ Department of Internal Medicine and Cardiology, \\ Campus Virchow-Klinikum, Charité - Universitätsmedizin Berlin, Berlin, Germany; 'Berlin Institute of Health \\ (BIH), Berlin, Germany; 'DZHK (German Centre for Cardiovascular Research), Partner Site Berlin, Berlin, Germany; \\ kDepartment of Nephrology and Dialysis, SS. Antonio e Biagio e Cesare Arrigo Hospital, Alessandria, Italy; 'Division \\ of Nephrology, Department of Internal Medicine, Dialysis and Transplantation, University of Genoa and IRCCS \\ Policlinico San Martino, Genoa, Italy
}

\section{Keywords}

Chronic kidney failure $\cdot$ Heart failure $\cdot$ Body water $\cdot$ Electric impedance - Telemedicine

\begin{abstract}
Background: Patients affected by chronic kidney disease are at a risk of cardiovascular morbidity and mortality. Body fluids unbalance is one of the main characteristics of this condition, as fluid overload is highly prevalent in patients affected by the cardiorenal syndrome. Summary: We describe the state of the art and new insights into body volume evaluation. The mechanisms behind fluid balance are often complex, mainly because of the interplay of multiple regulatory systems. Consequently, its management may be challenging in clinical practice and even more so out-of-hospital.
\end{abstract}

Availability of novel technologies offer new opportunities to improve the quality of care and patients' outcome. Development and validation of new technologies could provide new tools to reduce costs for the healthcare system, promote personalized medicine, and boost home care. Due to the current COVID-19 pandemic, a proper monitoring of chronic patients suffering from fluid unbalances is extremely relevant. Key Message: We discuss the main mechanisms responsible for fluid overload in different clinical contexts, including hemodialysis, peritoneal dialysis, and heart failure, emphasizing the potential impact provided by the implementation of the new technologies.

(C) 2021 The Author(s)

Published by S. Karger AG, Basel

Alessio Alogna and Pasquale Esposito are equally contributing last authors.
(C) 2021 The Author(s)

Published by S. Karger AG, Basel

This is an Open Access article licensed under the Creative Commons Attribution-NonCommercial-4.0 International License (CC BY-NC) (http://www.karger.com/Services/OpenAccessLicense), applicable to the online version of the article only. Usage and distribution for commercial purposes requires written permission. 


\section{Introduction}

The body fluid balance has always represented a critical issue in medicine since chronic and acute volume unbalances are negative prognostic factors in many different settings and conditions. In current practice, the concept of fluid balance and management has replaced the old idea of "hydration," a term used in the past to improperly describe the complex mechanisms behind the regulation of water and solutes in the human body. In this review, we describe the state of the art and new insights in body volumes evaluation and management in patients with chronic kidney disease (CKD), underlying the innovation opportunities provided by the implementation of new technologies.

\section{Fluid Volume Evaluation: An Overview}

First, it is important to distinguish the fluid volumes in the human body. The major volume is the total body water (TBW) [1], which in physiologic conditions represents a fixed percentage of the body weight. This percentage progressively decreases with ageing, and it is markedly influenced by the percentage of body fat and sex [2] TBW can be differentiated in sub-volumes (shown in Fig. 1): intracellular water (ICW) and extracellular water (ECW). In physiologic conditions, ICW accounts for around $2 / 3$ of TBW and $1 / 3$ of ECW.

ECW is more critical to define, representing the volume most exposed to fluid unbalance. It could be further subdivided into 2 volumes: intravascular (IV) and interstitial volume, the latter accounting for 3-4 times more fluid than the former in physiological conditions [3]. Finally, IV or plasma volume (PV) can also be partitioned in more specific sub-volumes, that is, arterial (30-40\%) and capacitance vessels (60-70\%) [4], while the interstitium can be divided in extracellular matrix and mesothelium (pleura, peritoneum, and tunica albuginea). Otherwise, in specific pathological conditions, other human compartments can accumulate an important amount of fluid, including the bowels, bladder, lungs, and pathologic cavities in soft tissue or parenchyma. In Table 1, we reported changes in fluid volumes distribution between physiological condition and kidney disease (shown in Fig. 1). Red blood cell volume is part of ICW in the description given above, but its analysis and evaluation, together with $\mathrm{PV}$, is of interest in the evaluation of the IV compartment [5].

Physiological and pathological values of volumes can be evaluated by different methods. The first approach historically used to measure the dimension and distribution of fluids in the human body is the indicator-dilution method. It is possible to calculate the volume of distribution of a specific substance starting from a basic correlation between mass volume and concentration: volume = mass/concentration. Injecting the human body with a known mass of a substance and then taking a sample of blood and measuring its concentration after equilibration, allows for volume of distribution of that specific substance to be calculated.

Since the first half of the last century, many substances with different distribution properties have been used to measure the various body fluid volumes. For example, deuterium oxide (heavy water), tritiated water [6,7], sodium bromide [8], and more recently radiosulfate have been used to measure TBW and ECW [9]. Dilution methods have also been used to quantify IV, by studying the volume distribution of plasma or red cells dyes, such as Evans blue, indocyanine green, iodine-131 (for plasma),

Table 1. Percentage changes in fluid distribution among body volumes in kidney disease [1-4, 80-82, 121-123]

\begin{tabular}{lllllll}
\hline & $\begin{array}{l}\text { TBW, } \\
\text { \% of BW }\end{array}$ & $\begin{array}{l}\text { ICW, } \\
\text { \% of TBW }\end{array}$ & $\begin{array}{l}\text { ECW, } \\
\text { \% of TBW }\end{array}$ & $\begin{array}{l}\text { IV, of ECW } \\
\% \text { of ECW }\end{array}$ & $\begin{array}{l}\text { Interstitial fluid, Reference } \\
\% \text { of }\end{array}$ \\
\hline Healthy man & 60 & 55 & 45 & 20 & 80 & {$[1-4]$} \\
Healthy woman & 50 & 55 & 45 & 20 & 80 & {$[1-4]$} \\
Nephrotic syndrome & $65-70$ & 40 & 60 & 15 & 85 & {$[121]$} \\
CKD early stage 1-3 & 60 & 55 & 45 & 20 & 80 & {$[122]$} \\
CKD advanced stage $4-5$ & 65 & 50 & 50 & 15 & 85 & {$[123]$} \\
CKD in dialysis & 70 & 40 & 60 & 15 & 85 & {$[80-82]$} \\
\hline
\end{tabular}

CKD, chronic kidney disease; TBW, total body water; ECW, extracellular water; ICW intracellular water; IV, intravascular volume.

Volume Evaluation in Chronic Kidney

Disease and Heart Failure
Kidney Blood Press Res 2021;46:396-410 DOI: $10.1159 / 000515172$ 

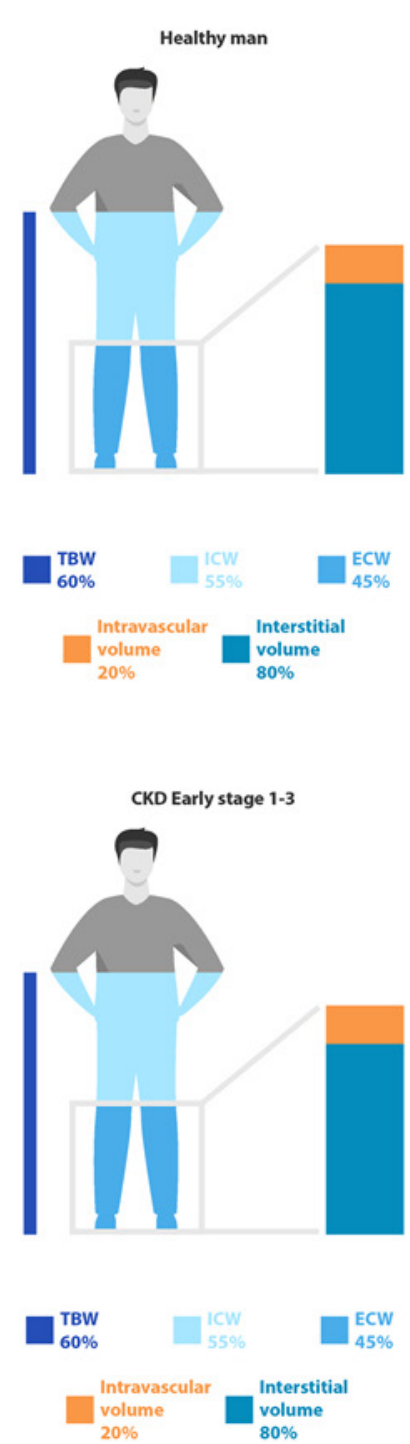
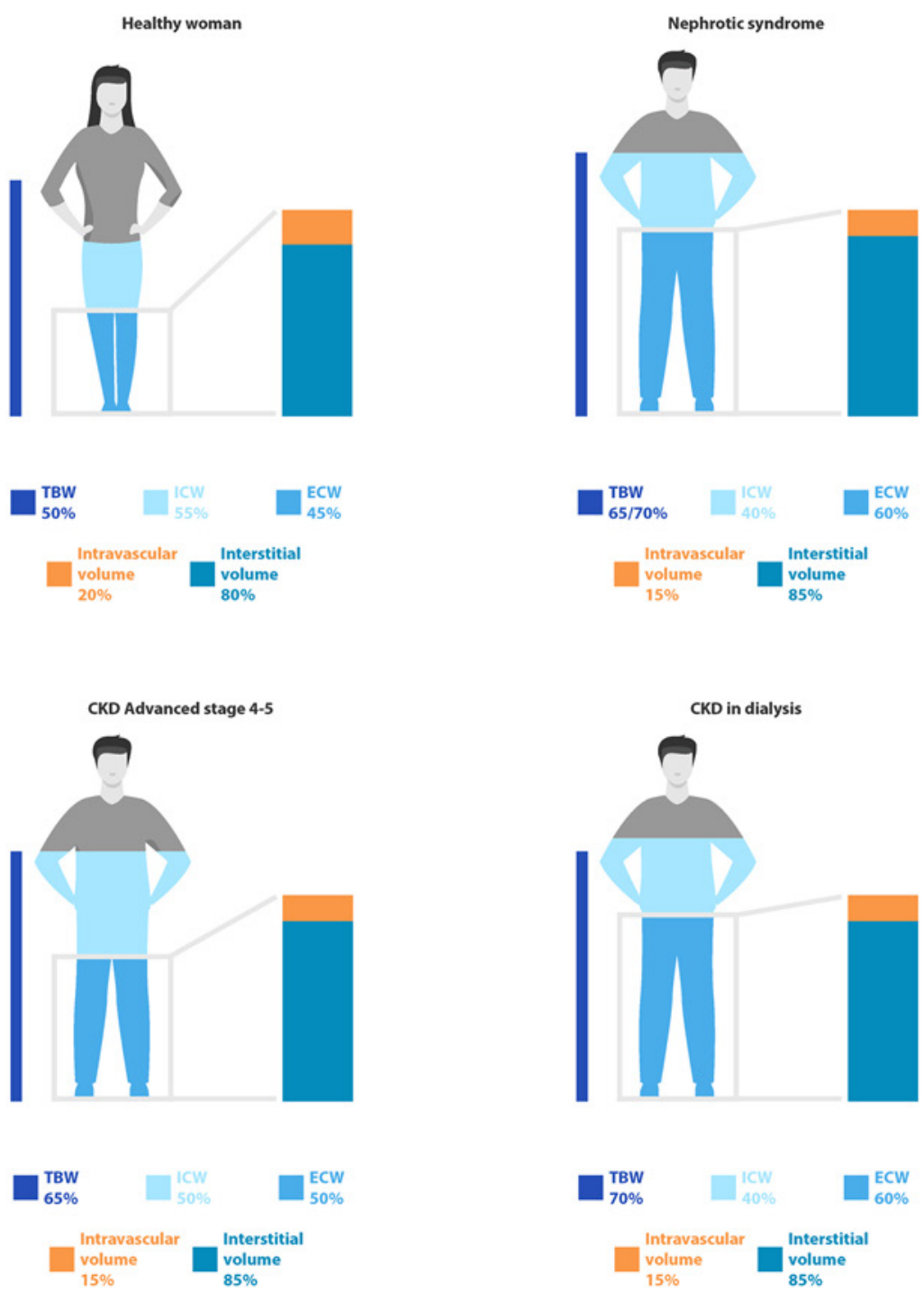

Fig. 1. Body fluids distribution in physiological condition and kidney disease. Graphic representation of different percentages of fluid distribution among CKD stages and nephrotic syndrome, with respect to physiological condition. CKD, chronic kidney disease.

carbon monoxide, and chromium-labelled red blood cells $[10,11]$. Anyway, dilution methods, despite their high accuracy, are limited to specific research uses, since they are invasive, expensive, and not easy to perform. Other methods have been developed to evaluate fluid volumes status that we can categorize in 2 groups: techniques of quantification and evaluation, that we listed in Table 2.

Quantification techniques, like dilution methods, measure one or more of the fluid volumes previously de- scribed and include noninvasive technologies, such as bioimpedance and magnetic resonance spectroscopy (MRS). Instead, evaluation techniques are heuristic methods that can help physicians in the clinical setting for the evaluation of the fluid volume status. They can include physical examination, blood pressure, central venous pressure (CVP) measurements, ultrasonography, biomarkers, etc. This distinction is not strict, but it is useful to facilitate the understanding of this topic. 
Table 2. Advantages and disadvantages of methods of volume quantification and evaluation [6-34]

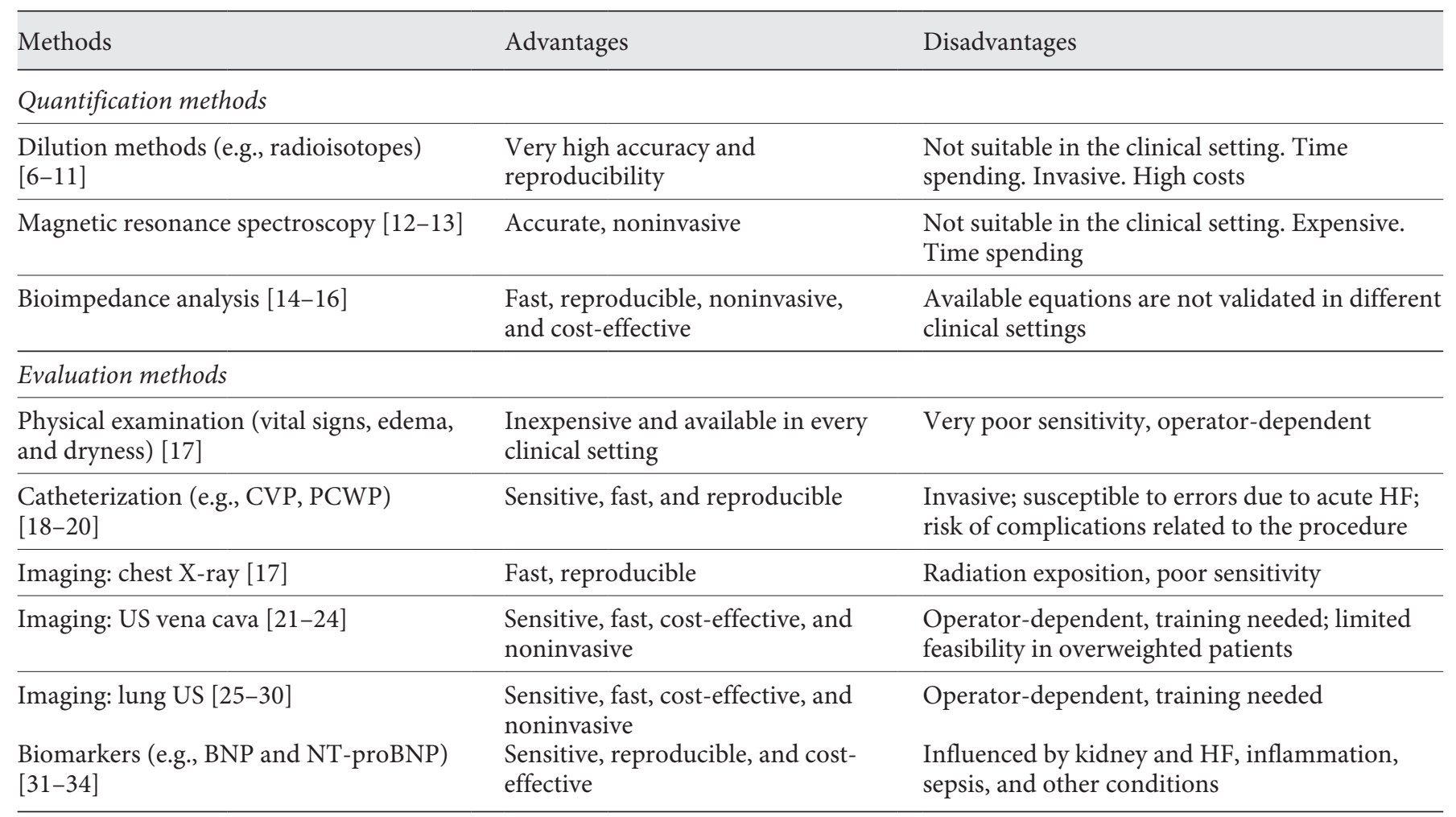

CVP, central venous pressure; PCWP, pulmonary capillary wedge pressure; US, ultrasound; BNP, brain natriuretic peptide; NTproBNP, N-terminal-pro-b-type natriuretic peptide; HF, heart failure.

\section{Techniques of Fluid Volume Quantification}

All methods that are able to quantify body fluid volumes belong to this group. The most well-known and used, in addition to dilution techniques, are MRS and bioimpedance analysis (BIA). MRS can be used both in vivo and in vitro studies, and it has a very wide scope of application in research, ranging from the study of organ metabolism and tissues to the measurement of body fluids, obtaining functional data together with anatomical evaluation [12]. Unlike magnetic resonance (MR), MRS can detect signals from atoms other than hydrogen such as phosphorus, carbon, and sodium providing information about adenosine triphosphate, glycolysis, and many other metabolites and metabolic pathways. Interestingly, a new MR technique has been described, the sodium MR that uses strong magnetic fields, magnetic field gradients, and radio waves to generate images of the distribution of sodium in the body. Coupled with conventional MRI, sodium MRI allows the absolute quantification of tissue sodium concentration and water content [13]. However, MRS and MR-based approaches are not suitable for clin- ical practice. On the other hand, techniques based on BIA are cost-effective, simple, and widely used in the clinical setting. BIA is based on the analysis of bioelectrical information obtained by the passage of an electrical impulse through the body to measure fat mass, fat-free mass, TBW, ECW, and ICW. Body water evaluation using BIA is based on the inverse correlation between resistance and the amount of fluids (water and electrolytes) [14]. Different BIA techniques and methods have been developed: whole-body tetrapolar or localized, single frequency or multifrequency, bioimpedance vectorial analysis, and bioimpedance spectroscopy.

These techniques usually work by using regressive equations built comparing collected data from their measurements with reference methods, such as dilution methods. The accuracy of these equations mainly depends on certain assumptions made during the "model building" phase and the statistical significance of the analyzed samples. For example, BIA equations developed in a setting of healthy and young subjects could give very inaccurate results when applied to elderly patients with sarcopenia 
[15]. Bioimpedance methods are also very helpful in the nutritional assessment in the clinical setting and the follow-up of the outpatients [16], especially in hemodialysis (HD) patients, as recently demonstrated by Battaglia et al. [17], that showed a high correlation between BIVA and muscle mass, measured with US technique.

\section{Techniques of Fluid Volume Evaluation}

These methods are not able to quantify body fluid volumes, but they provide information about volume status or hemodynamic assessment of patients. Depending on the clinical setting, invasive or noninvasive techniques can be used, including physical examination, measurement of blood pressure and the heart rate, X-ray, ultrasonography, and invasive hemodynamic monitoring or biomarkers. Physical evaluation and basic clinical parameters have lower specificity and sensitivity compared to more sophisticated methods, but represent a good starting point for further evaluations [18].

Invasive techniques do not provide a direct evaluation of volume status, but they are accurate methods for hemodynamic monitoring. Indeed, the measurements of CVP and pulmonary capillary wedge pressure agree with right and left atrial pressure are extremely useful for the hemodynamic assessment of critically ill patients [19]. Nevertheless, while central venous and arterial catheterization remain the most used for this method [20], other noninvasive hemodynamic markers, such as pulse pressure, systolic pressure variation, and stroke volume variation, can detect early phases of fluid unbalance [21]. Nonetheless, the evaluation of hemodynamic assessment should be interpreted together with the global clinical status and represents only an indication for the evaluation of the body volume status.

Ultrasonography is widely applied in the study of the inferior vena cava (IVC) size, which changes consistently with CVP and IV. Ultrasound evaluation of IVC is a bedside and noninvasive method of CVP estimation that provides quite a good correlation with the invasive measurement of CVP [22]. Physiologically, during inspiration, intrathoracic pressure becomes negative and intra-abdominal pressure increases, leading to increased venous return and a decreased IVC size (collapsibility index). Instead, in patients with fluid overload and venous congestion, the IVC size is frequently increased, and its physiological collapse decreased [23]. In 2015, the American Society of Echocardiography published a recommendation about ultrasound evaluation of IVC: the measurement should be taken with the patient in the supine position, from the subcostal view, with the IVC displayed along its long axis. No recommendations were given about the phase of the respiration to measure the maximum and the minimum diameter during the breathing. Moreover, the measurement of IVC collapsibility index (IVCCI) was recommended, where IVCCI $=($ IVC $\max -I V C \min ) /$ IVC max [24]. However, despite its routine use, this technique displays a significant inter-operator variability, that could be partially overcome simplifying the IVC measurements and performing short training sessions [25].

Lung ultrasound (LUS) has become, thanks to the possibility to identify pleural effusion and B-lines or "ringdown artefact," which are long, hyperechoic lines originating from the pleura, a bedside tool for the evaluation of central circulation congestion. In clinical practice and various scientific paper, B-lines are improperly associated to "comet-tail artefact," which instead are caused by different reflective interfaces [26].

Several LUS strategies to assess B-lines are used, based on the number of sectors examined and the B-lines count, and different scores have been proposed. The more Blines are detected, the more significant the result of the examination becomes and the worse the severity of the extracellular volume (ECV) overload [27]. One of the most used approaches, in different studies, employs the exploration of 28 sectors and $5 \mathrm{~B}$-lines as the threshold for a clinically significant pulmonary congestion [28]. Anyway, in the clinical routine, protocols with less sectors (e.g., 6-8 sectors) are usually preferred for point-of-care ultrasound [29,30]. Different probes and frequencies can be used to perform LUS, but an ultrasound penetration between 4 and $8 \mathrm{~cm}$ is recommended [31]. In the last several years, thanks to the improvement of artificial intelligence (AI), new methods of automatic detection and quantification of B-lines have been developed. These kinds of approaches have shown the potentialities to be advantageous in terms of faster data analysis and applicability to large sets of data without increased costs [32], and they will be probably adopted in the clinical setting in the coming years. Finally, several biomarkers have been studied for the evaluation of fluid volume status (both for fluid overload and hypovolemia), yet only a few of them have entered the daily clinical routine.

In the field of nephrology, the most simple and reliable markers to estimate fluid volume are serum blood urea nitrogen to creatinine ratio and fractional excretion of sodium. In particular, in states of hypovolemia with intact tubular function, blood urea nitrogen is expected to rise out of proportion to plasma creatinine concentration (serum urea/serum creatinine $>100$ ) [33], while urinary sodium excretion decreases (urinary sodium $<10-20$ 
$\mathrm{mmol} / \mathrm{L}$ or fractional excretion of sodium $<1 \%$ ) [34], due to avid urea and sodium reabsorption by the proximal tubule. These methods are not very specific, and they are affected by the underlying clinical conditions, such as in cases of concomitant renal and/or cardiac dysfunctions. Instead, biomarkers of heart failure (HF) such as B-type natriuretic peptide (BNP) or N-terminal-proBNP (NTproBNP) were shown to be helpful in the diagnosis of fluid overload, particularly in correlation with HF [35]. The concentration of these biomarkers increases in the bloodstream when left ventricular cardiomyocytes are stretched by preload, and are highly reproducible and widely available. However, the value of these volume biomarkers in the specific setting of CKD patients has been questioned due to evidence showing that they can accumulate in patients with renal dysfunction [36].

\section{Volume Balance and Evaluation in Different Clinical Settings of CKD Patients}

\section{Volume Balance in CKD and HF}

Patients with cardiac and renal diseases frequently show shared elements in their clinical presentation [37]. So, HF patients often manifest a degree of renal dysfunction, while CKD patients, especially in the later stages, present an increasing prevalence of cardiac disorders [38, 39]. Due to the tight connection between heart and kidney diseases, the term "cardiorenal syndrome" has been proposed to facilitate the classification of these conditions [40]. Cardiorenal syndrome comprises of a complex pathophysiology involving renin-angiotensin system activation, the sympathetic nervous system, and hemodynamic alterations [41]. The spectrum of kidney and heart diseases is very wide, but alterations of water balance and sodium handling are common pathogenetic features and important prognostic factors, considering that the presence of volume unbalance in these conditions is a predictor of worse outcome.

In CKD patients, sodium retention occurs as the result of the relationship between the glomerular filtration rate, sodium excretion, and ECV [42]. Indeed, while in normal subjects, at a steady state, there is a linear relationship between ECV and sodium excretion, which regulates blood pressure, in CKD this system is impaired [43].In CKD patients, salt ingestion is followed by an increase in sodium excretion per residual nephron, as a part of the adaptive response to reduced nephron number, leading to increased sodium excretion [44]. This response should be mediated by some degree of subclinical volume expan-

Volume Evaluation in Chronic Kidney Disease and Heart Failure sion and elevation in the mean arterial blood pressure, and represents a protection against the development of continuous sodium retention and edema formation.

However, this response seems limited in CKD and, most importantly, CKD patients are unable to further adequate sodium excretion in the presence of rapid changes in salt ingestion, so they are prone to develop volume expansion or depletion $[45,46]$. In addition, recent works by Titze [47] showed that sodium balance is more complex than previously thought, because of the presence of sodium storage in the skin. This finding is accentuated in CKD patients, and is correlated with left ventricular hypertrophy [48]. So, these pathophysiological alterations may create the conditions for a chronic ECV overload in CKD patients $[49,50]$.

Chronic fluid overload and LVH establish a vicious circle, as showed in recent study, fluid congestion evaluated with NT-proBNP and BIS measurements is strongly correlated to left ventricular mass index in patients with CKD [51]. To counteract fluid congestion in CKD, both diuretics and water restriction showed efficacy in reducing blood pressure and body fluids, evaluated with NTproBNP and body weight, without worsening the renal function [52]. On the other hand, in HF patients, the myocardial dysfunction causes arterial underfilling and reduction of renal blood flow, with the consequent reduction of the renal function (forward mechanism) [53]. These events lead to a systematic, sympathetic, and neurohormonal receptor activation; and the net movement of fluid to the IV to preserve organs perfusion [54].

To preserve glomerular capillary pressure (and so the glomerular filtration rate), the kidney can autoregulate through different mechanisms: myogenic adaptation of the glomerular afferent artery, the tubuloglomerular feedback, and the activation of the renin-angiotensin-aldosterone system $[55,56]$. On one hand, there is a continuous increase in fluids of the IV compartment, on the other hand, there is a net accumulation of interstitial fluid caused by an alteration in the capillary endothelial permeability [57]. The final effect of this pathway is the proportional increase of the IV and interstitium [58] (shown in Fig. 2). The consequent fluid overload, in turn, can determine the development of tissue hypertension and central venous congestion, which may lead to further worsening of the renal function, perpetuating a vicious circle (backward mechanism) [59].

\section{Volume Evaluation in CKD and HF}

The complexity of the physiopathology of the cardiorenal connections accounts for the difficulty of the fluid 


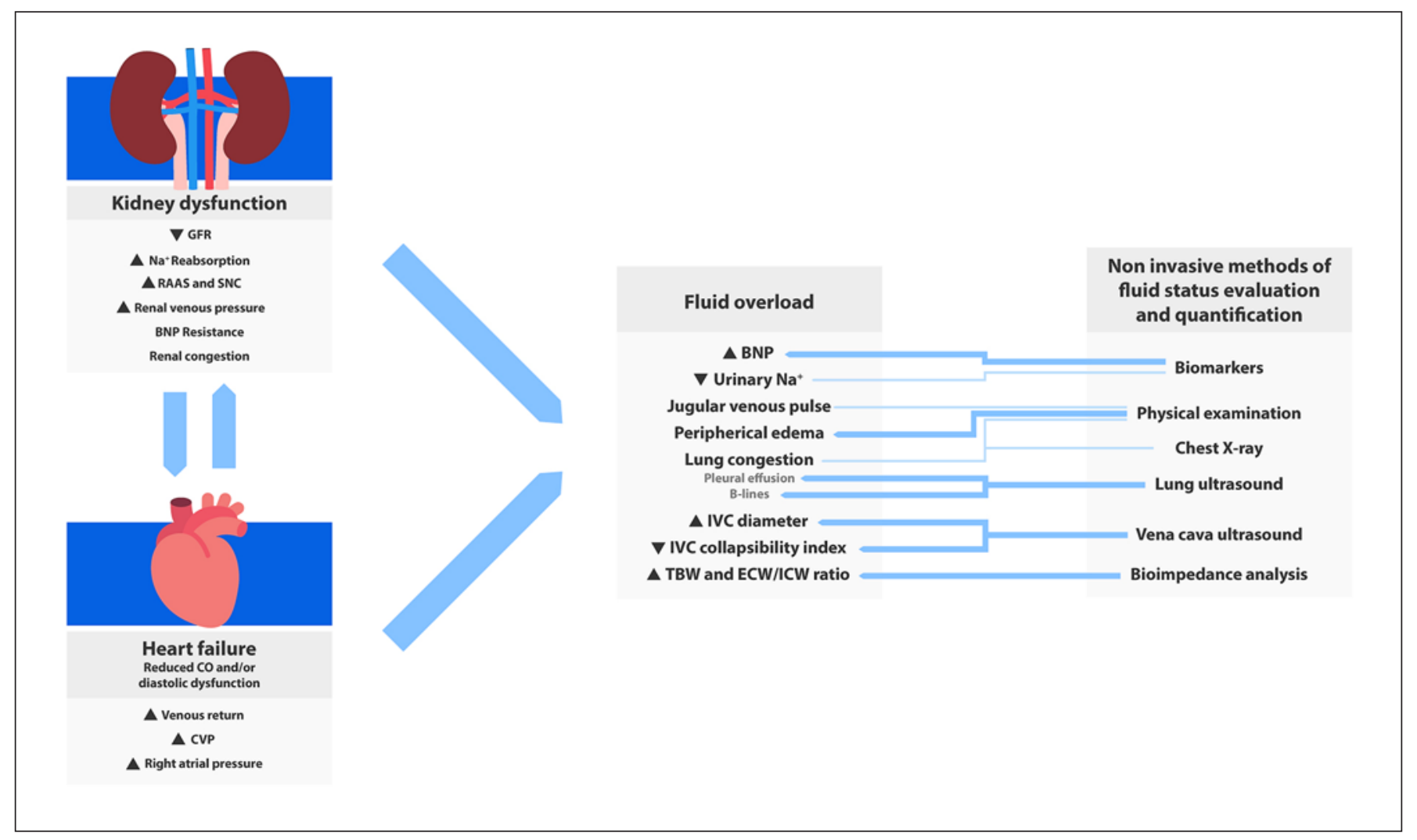

Fig. 2. Mechanisms underlying fluid overload in kidney dysfunction and HF, and noninvasive methods of fluid evaluation and quantification. HF and kidney dysfunction are strictly correlated and co-influenced and participate through various mechanism to establish and exacerbate fluid overload. Clinical and biochemical signs of fluid overload are heterogeneous, and fluid status evaluation is frequently challenging. A multiparametric approach using different noninvasive methods are the preferable approach in outpatients and not in critical patients to evaluate fluid status. Thick lines in the figure suggest most reliable methods. CVP, central venous pressure; ECW/ICW, extracellular and intracellular water; IVC, inferior vena cava; GFR, glomerular filtration rate; RAAS, renin-angiotensin-aldosterone system; SNS, sympathetic nervous system; TBW, total body water; HF, heart failure. volume assessment in these conditions. Fluid volume assessments are made more challenging by the lack of sensitivity and specificity of physical signs and symptoms (edema and dyspnea). Indeed, edema becomes clinically evident only when it is significant, and it can be present without systemic fluid expansion (e.g., vasodilatory drugs), while shortness of breath leads to $10-20 \%$ of false positives [60]. Individually, several indices of HF severity, such as elevated filling pressures, jugular venous pressure, orthopnea, and echocardiographic filling patterns, anticipate higher cardiovascular event rates. Other strategies of noninvasive fluid status assessment include evaluation of the levels of cardiac biomarkers, including natriuretic peptides and cardiac troponins that may also anticipate readmission risk, particularly if they remain high at hospital discharge [61, 62]. In acute HF invasive methods for evaluation of the hemodynamic status, such as pulmo- nary capillary wedge pressure, CVP, and pulmonary artery resistance could be very useful, for a comprehensive evaluation of the fluid status of a patient [63].

BNP and NT-proBNP are established markers of HF but, as reported above, the coexistence of a concomitant renal dysfunction could considerably change their interpretation. In general, $\mathrm{HF}$ is very likely at $\mathrm{BNP}$ values $>500$ $\mathrm{pg} / \mathrm{mL}$ and an NT-proBNP values $>450 \mathrm{pg} / \mathrm{mL}$, even if different cutoffs have been proposed, especially for patients with renal dysfunction [64]. The mechanisms underlying natriuretic peptides elevation in CKD patients are not fully understood. Cardiac wall stress, caused by fluid overload and subclinical ischemia is a tempting hypothesis, but the results from different studies are controversial [65].

Valle et al. [66] investigated a clinical approach based on natriuretic peptides and several BIA measurements for the fluid volume management. Patients were catego- 
Table 3. Telemedical trials in HF patients

\begin{tabular}{|c|c|c|c|c|c|}
\hline Study/author & Study type & $\begin{array}{l}\text { Patients no. and } \\
\text { characteristics }\end{array}$ & Intervention & Outcomes and comments & References \\
\hline $\begin{array}{l}\text { TELE-HF } \\
\text { Chaudhry et al. } \\
{[74]}\end{array}$ & $\begin{array}{l}\text { Multicenter randomized } \\
\text { controlled trial }\end{array}$ & $\begin{array}{l}1,653 \text { patients recently } \\
\text { hospitalized for } \mathrm{HF}\end{array}$ & $\begin{array}{l}\text { Telephone-based } \\
\text { interactive voice system }\end{array}$ & $\begin{array}{l}\text { Readmission or death within } 180 \\
\text { days. Not reached }\end{array}$ & {$[65]$} \\
\hline $\begin{array}{l}\text { BEAT-HF } \\
\text { Ong et al. [76] }\end{array}$ & $\begin{array}{l}\text { Multicenter randomized } \\
\text { controlled trial }\end{array}$ & $\begin{array}{l}1,437 \text { patients hospitalized } \\
\text { for } \mathrm{HF}\end{array}$ & $\begin{array}{l}\text { Health coaching telephone } \\
\text { call and telemonitoring }\end{array}$ & $\begin{array}{l}180 \text { days all-cause readmission. } \\
\text { Not reached }\end{array}$ & {$[67]$} \\
\hline $\begin{array}{l}\text { IN-TIME } \\
\text { Hindricks et al. } \\
{[77]}\end{array}$ & $\begin{array}{l}\text { Randomized controlled } \\
\text { trial }\end{array}$ & $\begin{array}{l}716 \text { patients NYHA class II } \\
\text { and III plus recent implant } \\
\text { of dual chamber ICD or } \\
\text { CRT-D with telemonitoring } \\
\text { function }\end{array}$ & $\begin{array}{l}\text { ICD or CRT-D } \\
\text { telemonitoring }\end{array}$ & $\begin{array}{l}\text { The composite clinical score: } \\
\text { death, admission, and change of } \\
\text { NYHA class. Significant } \\
\text { improvement of clinical outcomes }\end{array}$ & {$[68]$} \\
\hline $\begin{array}{l}\text { TIM-HF2 } \\
\text { Koehler et al. } \\
{[75]}\end{array}$ & $\begin{array}{l}\text { Multicenter randomized, } \\
\text { controlled, parallel- } \\
\text { group, unmasked trial }\end{array}$ & $\begin{array}{l}1,571 \text { patients NYHA class } \\
\text { II and III (EF }<45 \% \text { or EF } \\
>45 \% \text { and oral diuretics) }\end{array}$ & $\begin{array}{l}\text { Daily monitoring of body } \\
\text { weight, blood pressure, the } \\
\text { heart rate, } \mathrm{EKG}, \mathrm{SpO}_{2} \text {, and } \\
\text { a self-rated health status }\end{array}$ & $\begin{array}{l}\text { Reduce the percentage of days lost } \\
\text { due to unplanned cardiovascular } \\
\text { hospital admissions and all-cause } \\
\text { mortality }\end{array}$ & {$[66]$} \\
\hline
\end{tabular}

NYHA, New York Heart Association; ICD, implantable cardioverter defibrillator; CRT, cardiac resynchronization defibrillator; HF, heart failure.

rized as early responders, late responders, and nonresponders (based on the BNP fall after therapy), to allow physicians to identify high-risk patients. They report lower 6 months readmission rate in patients admitted to the hospital for acute $\mathrm{HF}$ and reduction of the health-care costs [66]. IVC diameter and IVCCI measured using point-of-care ultrasound are reliable indirect parameters of the right atrial pressure and volume status in HF [67]. A recent systematic review of the literature performed by Ciozda et al. [22] reports consistent findings in support of the use of IVC size for the estimation of CVP in nonmechanically ventilated patients. In particular, the IVC size was directly correlated to CVP, while IVCCI was shown to have a negative correlation. Anyway, IVC diameter measurement differences can exist between users. Moreover, other limitations consist of possible alterations to IVC measurement in the presence of diastolic dysfunction and the lack of normal values [68].

In recent years, LUS has been widely used and investigated in HF and CKD settings. In different studies, it has been demonstrated that lung ultrasonography has higher accuracy in detecting pleural effusion than bedside chest X-rays (96-93 vs. 65-47\%) [69]. Chest X-rays can detect pleural effusion only if the volume is at least $200 \mathrm{~mL}$, and the sensitivity of this method decreases in the supine position, whereas ultrasound can detect effusions as small as $20 \mathrm{~mL}$ [70]. A multidisciplinary panel of 28 experts has developed a consensus paper for LUS, based on those recommendations. B-lines show a very high correlation with the more established parameters of HF [71].

Volume Evaluation in Chronic Kidney

Disease and Heart Failure
Anyway, LUS has several limitations in the evaluation of volume status. For instance, some conditions (e.g., pulmonary fibrosis) cannot be differentiated from pulmonary congestion, and B-lines due to HF cannot be distinguished from acute respiratory distress syndrome of other origins. Finally, LUS cannot be used to evaluate volume depletion [72].

The importance of the follow-up in CKD and HF patients is crucial considering the high rate of rehospitalizations. The COVID-19 pandemic has made this even more challenging. In this new scenario, vulnerable populations, such as patients with multiple chronic conditions or immunosuppression, will face the difficult choice between risking iatrogenic COVID-19 exposure during a clinician visit and postponing needed care [73]. Different methods of remote monitoring of $\mathrm{CHF}$ and $\mathrm{CKD}$ patients were studied, and some methods have now become part of the clinical routine with a large disparity between one hospital and another. In Table 3, we reported a brief list of the main significant trials of the last decade. Noninvasive methods, however, have not been fully proven to be associated with a better outcome $[74,75]$. Concerning noninvasive methods, the most widespread involves regular telephone support to monitor the symptoms, the body weight measurement changes, and the psychological status of the patients [76]. The results of such remote monitoring are controversial, displaying both positive and negative results, the negative ones being mainly due to the low sensitivity of body weight changes [76]. However, the results of the TIM-HF2 trial published in 2018 suggest

Kidney Blood Press Res 2021;46:396-410 403 
that a structured remote patient management intervention could reduce the days lost due to unplanned cardiovascular hospital admissions and all-cause mortality [75].

One of the most effective approaches seems to be the use of invasive implanted devices, such as implantable cardioverter defibrillators and cardiac resynchronization therapy devices, which are able to detect potential arrhythmias and changes in thoracic congestion [77]. The IN-TIME trial which used automatic implant-based multiparameter telemonitoring (namely Biotronik Home Monitoring) controlling rhythmic, technical, and vital parameters was shown to decrease the mortality of HF patients [77]. Another extremely accurate way to predict decompensation events in HF patients is represented by the cardioMEMS, invasively implanted in the pulmonary artery to measure its pressure [78]. CardioMEMS has already been shown to decrease mortality and rehospitalizations, however, its utilization is still limited to endstage HF patients [78]. For both invasive and noninvasive solutions, what emerged clearly is not just one parameter, but multiple parameters should be used to detect patients at higher risk $[76,77]$.

Alternative approaches have also been reported. Recently, a multicentric research team tested different algorithms, using weight scale measurements and transthoracic bioimpedance data to predict HF decompensation events [79]. They demonstrated that, differently from weight scale measurements alone, the use of transthoracic BIA and weight scale in combination with trend algorithms, improved the detection of HF. BIA technology, more broadly, can also be very well miniaturized and embedded in wearable devices, increasing the range of opportunities to optimally mitigate CKD progression speed and maximizing the quality of life [80].

Another opportunity to increase the quality of life of chronic patients is given by voice-enabled technology and AI. Recently, a feasibility study was conducted to evaluate the quality of the data collection of a voice-enabled automated platform called CardioCube [81]. The use of AI, in particular machine learning (ML), to track the clinical status of HF outpatients has been evaluated in another recent study, using a wearable electrocardiogram with sensing patches. They developed an algorithm enabled to assess compensated and decompensated HF patients by analyzing cardiac response to submaximal exercise [82].

\section{Volume Balance in HD}

Despite medical improvements, the risk of mortality in HD patients remains approximately 30 times higher than the general population and 10-20 times higher after stratification for age, gender, and presence of diabetes [83]. Fluid volume management is an important component of cardiovascular risk [84] and several studies have reported that around $30 \%$ of dialysis patients are in chronic volume overload [85]. In extracorporeal dialysis, fluid removal is obtained by ultrafiltration (UF), a fluid transport from blood to dialysate, generated by the hydrostatic pressure gradient across the membrane. The optimal volume status of dialytic patients is usually described as dry weight, defined as the lowest tolerated postdialysis weight with minimal sign and symptoms of hypovolemia or hypervolemia [86]. Instead, interdialytic weight gain (IDWG) indicates the volume of fluids accumulated by the patient during the interdialytic period and that is necessary to remove during the single HD session by UF. When IDWG is excessive and consequently the UF rate is rapid, complications such as intradialytic hypotension, muscle cramps, nausea, or vomiting occur more frequently. The plasma refilling rate is a key factor during UF in hemodynamic balance. It has a very wide intraindividual and interindividual variability and can overcome $10 \mathrm{~mL} / \mathrm{kg} / \mathrm{min}$ [87]. In the dry-weight reduction in hypertensive HD patient trial, extreme IDWG was associated with adverse outcomes, while chronic volume overload was strongly correlated with mortality [88]. So, normalizing the ECV and avoiding a large IDWG should be primary clinical goals in the management of $\mathrm{HD}$ patients. Minimization of dietary sodium intake $(<1,500$ $\mathrm{mg} /$ day), an increase of dialysis time, and the reduction of dialysate sodium [89] have been described as valid methods to achieve these objectives. Moreover, in the HD setting, it should be considered that additionally a residual renal function (RRF) can be of significant help in maintaining the volume balance. Indeed, the presence of residual diuresis with loss of water and sodium with urine allows to reduce intradialytic fluid removal, decreasing the risk of intradialytic hypotension, chronic hypervolemia, HF, and consequently improves patient survival [90].

\section{Volume Evaluation}

Volume evaluation is challenging in HD patients since clinical examination and patient history are not always reliable. For example, hypertension may be a sign of volume overload, but it can also depend on sympathetic overactivity and/or increased arterial stiffness. Also, blood pressure is often influenced by lower left ventricular ejection fraction, cardiac valvular disease, malnutrition, and chronic wasting disease. Thus, hypertension is an important element guiding the assessment of dry 
weight, whereas the absence of hypertension does not necessarily indicate optimal fluid volume [91]. A HDspecific method to evaluate patient ECV is the relative PV monitoring, that, by use of photo-optical technology applied through a transparent chamber affixed to the arterial end of the dialyzer, allows measurement of the absolute changes of hematocrit during HD sessions.

Moreover, the assessment of IVC diameter, BNP and, in recent years, LUS has been studied as candidate indicators of volume status in HD patients $[92,93]$. LUS was deeply investigated in this clinical setting and the relationship between B-lines and UF; or IDWG and its prognostic value in the prediction of mortality; or CV events has been confirmed in different studies [94]. Furthermore, BIA methods are used to noninvasively measure TBW, ECW, and ICW; and to calculate lean mass and fat mass exploiting empirical equations. BIA is highly reproducible and operator independent. For this reason, it has been widely introduced in the HD setting [95]. Fluid overload measured with BIA (defined as overhydration/ ECW ratio $>7-15 \%$ ) [96] has shown a significant correlation with mortality, confirmed in different studies and metanalysis $[97,98]$. However, in a recent study, Mitsides et al. [99] speculated the possible influence of the subcutaneous sodium accumulation in reducing the predictive value and accuracy of BIA. A BIA-guided-HD approach has also been investigated in many trials and summarized in systematic reviews and meta-analyses. Studies have in general been successful in achieving secondary outcomes such as control of hypertension, as well as reducing fluid overload and hypotensive events, but there is still inconclusive evidence on hard outcomes such as mortality and hospitalization $[100,101]$. Further studies should be performed to better describe the effect of BIA-based strategies on survival in HD patients [50, 102]. Nowadays, due to the limitation of the UF rate, reaching a real improvement in volume management is still challenging without enhancing sodium water restriction or frequency of HD sessions. The fluid removal during adherent renal monitoring study, a prospective, nonrandomized trial, examined the performance of a noninvasive, multisensor fluid monitoring system, applied to the chest, to determine its performance and reliability during HD. Compared with body weight, bioimpedance showed a more sensitive detection of changes in the body fluid [103]. Even with these new approaches, achieving the optimal balance between $\mathrm{UF}$ and the risk of intradialytic hypotensive events is a complex task in clinical practice. ML may help to personalize the multiple dialysis-related prescriptions affecting patients' intradialytic hemodynamics. One of the progen-

Volume Evaluation in Chronic Kidney Disease and Heart Failure itors of this approach is the automatic control of blood volume [104], such as the hemocontrol biofeedback system (Hemocontrol ${ }^{\mathrm{TM}}$, Hospal, Italy) that modifies sodium concentration of dialysate and regulates the UF rate through a biofeedback mechanism, based on relative PV [105]. Successively, different predictive models for session-specific endpoints (such as $\mathrm{Kt} / \mathrm{V}$, fluid volume removal, and blood pressure) have been proposed, with encouraging results, based on patient characteristics, historic hemodynamic responses, and dialysis-related prescriptions [106]. ML works using interconnected processing units organized, inspired by the neurons in the human brain. ML learns to compute a specific input-output mapping by tuning a set of parameters in response to being exposed to a sufficiently large set of data [107]. The results of a ML analysis can assist physicians in decisionmaking via early detection of vital parameters such as blood pressure, the heart rate, the respiration rate, and body temperature, available through the artificial kidney [108]. This kind of online monitoring systems with automatic biofeedback in combination with progress in nanotechnology has made possible the implementation of home HD [109], as well as the development of the wearable artificial kidney and implantable bioartificial kidney, still in the preclinical study stage [110]. The clinical setting is complex and requires a multiparameter approach. In this scenario, AI and new technologies may improve the diagnosis and treatment under medical surveillance.

\section{Volume Balance in Peritoneal Dialysis}

Peritoneal dialysis (PD) is performed by the patient or the caregiver at their own home and presents some peculiarities in respect to HD in the mechanisms regulating fluid management. Indeed, in PD, the water is removed mainly by osmosis and is regulated by Starling forces through the peritoneum. Therefore, the rate of water removal is dependent on the osmolality of the intraperitoneal solutions, which induce an osmotic gradient between the peritoneal cavity and the peritoneal vessels with the consequent transfer of water into the peritoneal cavity through a crystalidosmosis process [111]. The commonly used solutions contain glucose at different concentrations $(1.36,2.27$, and $3.86 \%)$ and UF is increased by increasing the concentration of glucose in the peritoneal dialysate [111]. Because of the absorption of glucose from the peritoneal cavity into the capillaries, the osmotic efficiency of the glucose-containing solutions is reduced during the dwell. Icodextrin, a glucose polymer, is reabsorbed only to a small extent by the peritoneum, and therefore induces UF that lasts over time through a col- 
loid osmosis mechanism [112]. The choice of peritoneal solution usage depends on the clinical needs of each patient, allowing for personalization of the treatment. Moreover, $\mathrm{PD}$ is associated with better preservation of the RRF than $\mathrm{HD}$, because of a lower frequency of volume depletion episodes [113]. However, despite these advantageous factors, volume unbalance is also common in PD patients. A recent prospective study by Van Biesen et al. [114] found a significant amount of volume unbalances in a cohort of 1,054 incidental PD patients. In particular, a relative volume overload of $>7 \%$, detected with BIA was present in $57 \%$ of the participants before the start of PD and persisted after 1, 2, and 3 years of follow-up (48, 49, and $53 \%$ of the patients, respectively). As for HD, in PD, volume excess can be harmful as well and it is associated with left ventricular dysfunction and hypertension, that in turn correlates with worse survival, also considering that cardiovascular complications are responsible for $40-60 \%$ of deaths in PD patients [115].

\section{Volume Evaluation}

Fluid volume assessment in PD is carried out exploiting the same techniques described before. Physical examination is part of the routine evaluation of $\mathrm{PD}$ patients and can be used together with blood pressure measurements, imaging, and natriuretic peptides. However, clinical examination often proves to be imprecise and incapable of guiding practicing nephrologists to more appropriate PD prescriptions. BIA has been increasingly employed in the evaluation of volume status in PD patients, as it can be easily performed by patients themselves at home. However, even if it might be theoretically useful, it should be also admitted that available data do not strongly support the claim that BIA is useful in the management of volume status. A prospective trial by Tan et al. [116] tried to determine the clinical impact of the longitudinal plot of the BIA analysis vector (i.e., the direction in which fluid status is changing). Unfortunately, the authors found that the intervention did not result in further improvement in fluid analysis measurements [116]. The COMPASS study evaluated the usefulness of BIA in preserving RRF and CV function in non-anuric PD patients [117]. The authors found that when compared with the control group receiving only clinical evaluation, patients receiving BIA-guided fluid management did not present significant clinical benefits. Although not generalizable, these results at the least indicate that further research is warranted to investigate the role of BIA in PD patient volume management. One of the most peculiar aspects of $\mathrm{PD}$ is that the treatment is delivered at patient's home, both in the case of use of manual (i.e., continuous ambulatoryPD) and automated exchanges (i.e., automated-PD). So, this technique is suitable for the widespread adoption of telemedicine platforms, which could be of great support for the patients.

A prototypical PD-telemedicine platform would allow for fast communication between patients and health-care providers while remaining nonintrusive and portable. Notably, in the telemonitoring systems, many important parameters could be considered, including peritoneal volumes, blood pressure, body weight, and BIA [118]. So, the adoption of this strategy can provide useful real-life information on volume status and control. Interestingly, recent studies performed in Europe [119] and Asia [120] found that telemonitored $\mathrm{PD}$ patients presented low rates of technique failures and hospitalizations, as well as reduced overall costs.

\section{Conclusions}

Body fluid management is one of the most important issues in the clinical practice. The first step to improve the quality of care provided to our patients and clinical outcomes is to understand the physiopathology behind body fluid unbalances. This challenging task should take advantage of basic research and clinical trials to achieve a better knowledge of the relationship between the heart and kidney, molecular signal pathways, and adaptive response in kidney disease. The second step is refining our diagnostic methods and remote monitoring techniques, to allow real-time evaluation of the fluid status of a patient in and out of the hospital. This will be possible thanks to the application of new technologies, like telemedicine, wearable devices, nanotechnologies, the AI-medical support system, and bioengineering. In particular, progress in AI will likely allow us to overcome the human diagnostic threshold, leading to a quality of care that is unconceivable nowadays. The need to develop these tools comes from the necessity to reduce costs for the health-care system, incentive personalized medicine, provide health assistance to a wide number of people, and it has been further exacerbated by the recent emerging necessity to monitor chronic patients in the midst of the COVID-19 pandemic. Once regulatory and ethic barriers are removed, and as soon as AI-based techniques prove to be effective, we will be probably seeing an exponential spread of automated medical support systems for real personalized healthcare, without any increase in workload for medical personnel and reduced admissions to hospitals and the related costs. 


\section{Acknowledgements}

We thank Simone Proietti Timperi for performing the graphical illustrations.

\section{Conflict of Interest Statement}

Alessandro Faragli and Edoardo La Porta are shareholders of the company BOCA health-care $\mathrm{GmbH}$. Other authors declare no conflicts of interest.

\section{Funding Sources}

We acknowledge support from the German Research Foundation (DFG) and the Open Access Publication Fund of Charité Universitätsmedizin Berlin.

\section{Author Contributions}

E.L.P. provided the idea, collected the literature, and wrote the manuscript; L.L., M.C., E.C., L.E., A.A.V., and A.F. collected the literature and wrote the manuscript; A.A.L., C.Q., and P.E. revised the manuscript.

\section{References}

1 Watson PE, Watson ID, Batt RD. Total body water volumes for adult males and females estimated from simple anthropometric measurements. Am J Clin Nutr. 1980;33(1):2739.

2 Schoeller DA. Changes in total body water with age. Am J Clin Nutr. 1989;50(5):1176-5.

3 Woodcock TE, Woodcock TM. Revised starling equation and the glycocalyx model of transvascular fluid exchange: an improved paradigm for prescribing intravenous fluid therapy. Br J Anaesth. 2012;108(3):384-94.

4 Fink GD. Arthur C. Corcoran memorial lecture. Sympathetic activity, vascular capacitance, and long-term regulation of arterial pressure. Hypertension. 2009;53(2):307-12.

5 Lobigs LM, Sottas P-E, Bourdon PC, Nikolovski Z, El-Gingo M, Varamenti E, et al. The use of biomarkers to describe plasma-, red cell-, and blood volume from a simple blood test: development of a marker to describe blood volumes. Am J Hematol. 2017;92(1): 62-7.

6 Degen AA, Pinshow B, Alkon PU, Arnon H. Tritiated water for estimating total body water and water turnover rate in birds. J Appl Physiol Respir Environ Exerc Physiol. 1981; 51(5):1183-8.

7 Van Marken Lichtenbelt WD, Westerterp KR, Wouters L. Deuterium dilution as a method for determining total body water: effect of test protocol and sampling time. Br J Nutr. 1994;72(4):491-7.

8 Thomas LD, Velde DV, Schloerb PR. Optimum doses of deuterium oxide and sodium bromide for the determination of total body water and extracellular fluid. J Pharm Biomed Anal. 1991;9(7):581-4.

9 Bauer J, Burt R, Whang R, Grim C. Simultaneous determination of extracellular fluid and total body water. I. J Lab Clin Med. 1975 Dec; 86(6):1003-8.

10 Bradley EC, Barr JW. Determination of blood volume using indocyanine green (CardioGreen $^{\circledast}$ ) dye. Life Sci. 1968;7(17):1001-7.

11 Gray SJ, Sterling K. The tagging of red cells and plasma proteins with radioactive chromium 1. J Clin Invest. 1950;29(12):1604-13.
12 Tognarelli JM, Dawood M, Shariff MIF, Grover VPB, Crossey MME, Cox IJ, et al. Magnetic resonance spectroscopy: principles and techniques: lessons for clinicians. J Clin Exp Hepatol. 2015;5(4):320-8.

13 Kopp C, Linz P, Wachsmuth L, Dahlmann A, Horbach T, Schöfl C, et al. (23)Na magnetic resonance imaging of tissue sodium. Hypertension. 2012;59(1):167-72.

14 Lukaski HC, Johnson PE, Bolonchuk WW, Lykken GI. Assessment of fat-free mass using bioelectrical impedance measurements of the human body. Am J Clin Nutr. 1985;41(4): 810-7.

15 Bussolotto M, Ceccon A, Sergi G, Giantin V, Benincà $P$, Enzi G. Assessment of body composition in elderly: accuracy of bioelectrical impedance analysis. Gerontology. 1999;45(1): 39-43.

16 Kondrup J, Allison SP, Elia M, Vellas B, Plauth M. ESPEN guidelines for nutrition screening 2002. Clin Nutr. 2003;22(4):41521.

17 Battaglia Y, Ullo I, Massarenti S, Esposito P, Prencipe M, Ciancio G, et al. Ultrasonography of quadriceps femoris muscle and subcutaneous fat tissue and body composition by BIVA in chronic dialysis patients. Nutrients. 2020;12(5): 1388 .

18 Chakko S, Woska D, Martinez H, de Marchena E, Futterman L, Kessler KM, et al. Clinical, radiographic, and hemodynamic correlations in chronic congestive heart failure: conflicting results may lead to inappropriate care. Am J Med. 1991;90(3):353-9.

19 Litton E, Morgan M. The PiCCO monitor: a review. Anaesth Intensive Care. 2012;40(3): 393-409.

20 Michard F, Teboul J-L. Predicting fluid responsiveness in ICU patients: a critical analysis of the evidence. Chest. 2002;121(6):2000 8.

21 Reuter DA, Felbinger TW, Schmidt C, Kilger E, Goedje O, Lamm P, et al. Stroke volume variations for assessment of cardiac responsiveness to volume loading in mechanically ventilated patients after cardiac surgery. Intensive Care Med. 2002;28(4):392-8.
22 Ciozda W, Kedan I, Kehl DW, Zimmer R, Khandwalla R, Kimchi A. The efficacy of sonographic measurement of inferior vena cava diameter as an estimate of central venous pressure. Cardiovasc Ultrasound. 2015;14(1): 33.

23 Zhu F, Rosales L, Kotanko P. Techniques for assessing fluids status in patients with kidney disease. Curr Opin Nephrol Hypertens. 2016; 25(6):473-9.

24 Porter TR, Shillcutt SK, Adams MS, Desjardins G, Glas KE, Olson JJ, et al. Guidelines for the use of echocardiography as a monitor for therapeutic intervention in adults: a report from the American society of echocardiography. J Am Soc Echocardiogr. 2015;28(1):4056.

25 David Martin L, Ziegelstein RC, Howell EE, Martire C, Hellmann DB, Hirsch GA. Hospitalists' ability to use hand-carried ultrasound for central venous pressure estimation after a brief training intervention: a pilot study: IVC ultrasound imaging training. J Hosp Med. 2013;8(12):711-4.

26 Fiorini F, Zanforlin A, D’Amelio A, Battaglia Y, Zamboli P, Granata A. [Chest ultrasound in nephrology]. G Ital Nefrol. 2014;31(3).

27 Buessler A, Chouihed T, Duarte K, Bassand A, Huot-Marchand M, Gottwalles Y, et al. Accuracy of several lung ultrasound methods for the diagnosis of acute heart failure in the ED: a Multicenter Prospective Study. Chest. 2020; 157(1):99-110.

28 Frassi F, Gargani L, Tesorio P, Raciti M, Mottola G, Picano E. Prognostic value of extravascular lung water assessed with ultrasound lung comets by chest sonography in patients with dyspnea and/or chest pain. J Card Fail. 2007;13(10):830-5

29 Lichtenstein DA. BLUE-protocol and FALLSprotocol: two applications of lung ultrasound in the critically ill. Chest. 2015;147(6):165970.

30 Lichtenstein DA, Mezière GA. Relevance of lung ultrasound in the diagnosis of acute respiratory failure: the BLUE protocol. Chest. 2008;134(1):117-25.
Volume Evaluation in Chronic Kidney Disease and Heart Failure 
31 Dietrich CF, Mathis G, Blaivas M, Volpicelli G, Seibel A, Wastl D, et al. Lung B-line artefacts and their use. J Thorac Dis. 2016;8(6): 1356-65.

32 Brusasco C, Santori G, Bruzzo E, Trò R, Robba C, Tavazzi G, et al. Quantitative lung ultrasonography: a putative new algorithm for automatic detection and quantification of Blines. Crit Care. 2019;23(1):288.

33 Macedo E, Mehta RL. Prerenal failure: from old concepts to new paradigms. Curr Opin Crit Care. 2009;15(6):467-73.

34 Miller TR. Urinary diagnostic indices in acute renal failure: a Prospective Study. Ann Intern Med. 1978;89(1):47.

35 Troughton R, Michael Felker G, Januzzi JL. Natriuretic peptide-guided heart failure management. Eur Heart J. 2014;35(1):16-24.

36 Parikh CR, Mansour SG. Perspective on clinical application of biomarkers in AKI. J Am Soc Nephrol. 2017;28(6):1677-85.

37 Deferrari G, Cipriani A, La Porta E. Renal dysfunction in cardiovascular diseases and its consequences. J Nephrol. 2021;34(1):137-53.

38 Levin A, Singer J, Thompson CR, Ross H, Lewis M. Prevalent left ventricular hypertrophy in the predialysis population: identifying opportunities for intervention. Am J Kidney Dis. 1996;27(3):347-54.

39 Smith GL, Lichtman JH, Bracken MB, Shlipak MG, Phillips CO, DiCapua P, et al. Renal impairment and outcomes in heart failure: systematic review and meta-analysis. J Am Coll Cardiol. 2006;47(10):1987-96.

40 Ronco C, McCullough P, Anker SD, Anand I, Aspromonte N, Bagshaw SM, et al. Cardiorenal syndromes: report from the consensus conference of the acute dialysis quality initiative. Eur Heart J. 2010;31(6):703-11.

41 Tsuruya K, Eriguchi M. Cardiorenal syndrome in chronic kidney disease. Curr Opin Nephrol Hypertens. 2015;24(2):154-62.

42 Khan S, Floris M, Pani A, Rosner MH. Sodium and volume disorders in advanced chronic kidney disease. Adv Chronic Kidney Dis. 2016;23(4):240-6.

43 Lerchl K, Rakova N, Dahlmann A, Rauh M, Goller U, Basner M, et al. Agreement between 24-hour salt ingestion and sodium excretion in a controlled environment. Hypertension. 2015;66(4):850-7.

44 Thakar S, Paller MS. Sodium metabolism in chronic kidney disease. Chronic Renal Dis. 2020;633-41.

45 Vasavada N, Agarwal R. Role of excess volume in the pathophysiology of hypertension in chronic kidney disease. Kidney Int. 2003; 64(5):1772-9.

46 Danovitch GM, Bourgoignie J, Bricker NS. Reversibility of the "salt-losing" tendency of chronic renal failure. N Engl J Med. 1977; 296(1):14-9.

47 Titze J. A different view on sodium balance. Curr Opin Nephrol Hypertens. 2015;24(1): 14-20.

48 Schneider MP, Raff U, Kopp C, Scheppach JB, Toncar S, Wanner C, et al. Skin sodium con- centration correlates with left ventricular hypertrophy in CKD. J Am Soc Nephrol. 2017; 28(6):1867-76.

49 McCullough PA, Chan CT, Weinhandl ED, Burkart JM, Bakris GL. Intensive hemodialysis, left ventricular hypertrophy, and cardiovascular disease. Am J Kidney Dis. 2016; 68(5):S5-14.

50 Onofriescu M, Hogas S, Voroneanu L, Apetrii M, Nistor I, Kanbay M, et al. Bioimpedanceguided fluid management in maintenance hemodialysis: a pilot randomized controlled trial. Am J Kidney Dis. 2014;64(1):111-8.

51 Han B-G, Lee JY, Kim MR, Shin H, Kim J-S Yang J-W, et al. Fluid overload is a determinant for cardiac structural and functional impairments in type 2 diabetes mellitus and chronic kidney disease stage 5 not undergoing dialysis. PLoS One. 2020;15(7):e0235640.

52 Bovée DM, Visser WJ, Middel I, De Mik-van Egmond A, Greupink R, Masereeuw R, et al. A randomized trial of distal diuretics versus dietary sodium restriction for hypertension in chronic kidney disease. J Am Soc Nephrol. 2020;31(3):650-62.

53 Gilbert C, Cherney DZI, Parker AB, Mak S, Floras JS, Al-Hesayen A, et al. Hemodynamic and neurochemical determinates of renal function in chronic heart failure. Am J Physiol Regul Integr Comp Physiol. 2016;310(2): R167-75.

54 Metra M, Teerlink JR. Heart failure. Lancet. 2017;390(10106):1981-95.

55 Evans RG, Gardiner BS, Smith DW, O’Connor PM. Intrarenal oxygenation: unique challenges and the biophysical basis of homeostasis. Am J Physiol Renal Physiol. 2008;295(5): F1259-70.

56 Gloviczki ML, Lerman LO, Textor SC. Blood oxygen level-dependent (BOLD) MRI in renovascular hypertension. Curr Hypertens Rep. 2011;13(5):370-7.

57 Cotter G, Metra M, Milo-Cotter O, Dittrich HC, Gheorghiade M. Fluid overload in acute heart failure: re-distribution and other mechanisms beyond fluid accumulation. Eur J Heart Fail. 2008;10(2):165-9.

58 Schnermann J. The juxtaglomerular apparatus: from anatomical peculiarity to physiological relevance. J Am Soc Nephrol. 2003;14(6): 1681-94.

59 Mullens W, Abrahams Z, Francis GS, Sokos G, Taylor DO, Starling RC, et al. Importance of venous congestion for worsening of renal function in advanced decompensated heart failure. J Am Coll Cardiol. 2009;53(7):589-96.

60 Agarwal R, Andersen MJ, Pratt JH. On the importance of pedal edema in hemodialysis patients. Clin J Am Soc Nephrol. 2008;3(1):1538.

61 Kociol RD, Horton JR, Fonarow GC, Reyes EM, Shaw LK, O'Connor CM, et al. Admission, discharge, or change in B-type natriuretic peptide and long-term outcomes: data from organized program to initiate lifesaving treatment in hospitalized patients with heart failure (OPTIMIZE-HF) linked to medicare claims. Circ Heart Fail. 2011; 4(5):628-36.

62 Dunlay SM, Gheorghiade M, Reid KJ, Allen LA, Chan PS, Hauptman PJ, et al. Critical elements of clinical follow-up after hospital discharge for heart failure: insights from the EVEREST trial. Eur J Heart Fail. 2010;12(4): 367-74

63 Jain CC, Borlaug BA. Hemodynamic assessment in heart failure. Catheter Cardiovasc Interv. 2020;95(3):420-8.

64 Jafri L, Kashif W, Tai J, Siddiqui I, Azam I, Shahzad H, et al. B-type natriuretic peptide versus amino terminal pro-B type natriuretic peptide: selecting the optimal heart failure marker in patients with impaired kidney function. BMC Nephrol. 2013;14(1):117.

65 Safley DM, Awad A, Sullivan RA, Sandberg KR, Mourad I, Boulware M, et al. Changes in B-type natriuretic peptide levels in hemodialysis and the effect of depressed left ventricular function. Adv Chronic Kidney Dis. 2005; 12(1):117-24.

66 Valle R, Aspromonte N, Milani L, Peacock FW, Maisel AS, Santini M, et al. Optimizing fluid management in patients with acute decompensated heart failure (ADHF): the emerging role of combined measurement of body hydration status and brain natriuretic peptide (BNP) levels. Heart Fail Rev. 2011;16(6):519-29.

67 Goonewardena SN, Gemignani A, Ronan A, Vasaiwala S, Blair J, Brennan JM, et al. Comparison of hand-carried ultrasound assessment of the inferior vena cava and $\mathrm{N}$-terminal pro-brain natriuretic peptide for predicting readmission after hospitalization for acute decompensated heart failure. JACC Cardiovasc Imaging. 2008;1(5):595-601.

68 Krause I, Birk E, Davidovits M, Cleper R, Blieden L, Pinhas L, et al. Inferior vena cava diameter: a useful method for estimation of fluid status in children on haemodialysis. Nephrol Dial Transplant. 2001;16(6):1203-6.

69 Lichtenstein D, Goldstein I, Mourgeon E, Cluzel P, Grenier P, Rouby J-J. Comparative diagnostic performances of auscultation, chest radiography, and lung ultrasonography in acute respiratory distress syndrome. Anesthesiology. 2004;100(1):9-15.

70 Rahman NM, Singanayagam A, Davies HE, Wrightson JM, Mishra EK, Lee YCG, et al. Diagnostic accuracy, safety and utilisation of respiratory physician-delivered thoracic ultrasound. Thorax. 2010;65(5):449-53.

71 Yang F, Wang Q, Zhi G, Zhang L, Huang D, Shen $\mathrm{D}$, et al. The application of lung ultrasound in acute decompensated heart failure in heart failure with preserved and reduced ejection fraction. Echocardiography. 2017; 34(10):1462-9.

72 Covic A, Siriopol D, Voroneanu L. Use of lung ultrasound for the assessment of volume status in CKD. Am J Kidney Dis. 2018;71(3): $412-22$.

73 Keesara S, Jonas A, Schulman K. Covid-19 and health care's digital revolution. $\mathrm{N}$ Engl Med. 2020;382(23):e82. 
74 Chaudhry SI, Mattera JA, Curtis JP, Spertus JA, Herrin J, Lin Z, et al. Telemonitoring in patients with heart failure. N Engl J Med. 2010;363(24):2301-9.

75 Koehler F, Koehler K, Deckwart O, Prescher S, Wegscheider K, Kirwan B-A, et al. Efficacy of telemedical interventional management in patients with heart failure (TIM-HF2): a randomised, controlled, parallel-group, unmasked trial. Lancet. 2018;392(10152):104757.

76 Ong MK, Romano PS, Edgington S, Aronow $\mathrm{HU}$, Auerbach AD, Black JT, et al. Effectiveness of remote patient monitoring after discharge of hospitalized patients with heart failure: the better effectiveness after transition-heart failure (BEAT-HF) randomized clinical trial. JAMA Intern Med. 2016; 176(3):310

77 Hindricks G, Taborsky M, Glikson M, Heinrich U, Schumacher B, Katz A, et al. Implantbased multiparameter telemonitoring of patients with heart failure (IN-TIME): a randomised controlled trial. Lancet. 2014; 384(9943):583-90.

78 Gronda E, Vanoli E, Zorzi A, Corrado D. CardioMEMS, the real progress in heart failure home monitoring. Heart Fail Rev. 2020;25(1): 93-8.

79 Cuba Gyllensten I, Bonomi AG, Goode KM, Reiter H, Habetha J, Amft O, et al. Early indication of decompensated heart failure in patients on home-telemonitoring: a comparison of prediction algorithms based on daily weight and noninvasive transthoracic bio-impedance. JMIR Med Inform. 2016;4(1):e3.

80 Wieringa FP, Broers NJH, Kooman JP, Van Der Sande FM, Van Hoof C. Wearable sensors: can they benefit patients with chronic kidney disease? Expert Rev Med Devices. 2017;14(7):505-19.

81 Jadczyk T, Kiwic O, Khandwalla RM, Grabowski K, Rudawski S, Magaczewski P, et al. Feasibility of a voice-enabled automated platform for medical data collection: CardioCube. Int J Med Inform. 2019;129:388-93.

82 Inan OT, Baran Pouyan M, Javaid AQ, Dowling S, Etemadi M, Dorier A, et al. Novel wearable seismocardiography and machine learning algorithms can assess clinical status of heart failure patients. Circ Heart Fail. 2018; 11(1):e004313.

83 Goodkin DA. Association of comorbid conditions and mortality in hemodialysis patients in Europe, Japan, and the United States: the dialysis outcomes and practice patterns study (DOPPS). J Am Soc Nephrol. 2003;14(12): 3270-7.

84 Weiner DE, Brunelli SM, Hunt A, Schiller B, Glassock R, Maddux FW, et al. Improving clinical outcomes among hemodialysis patients: a proposal for a "volume first" approach from the chief medical officers of US dialysis providers. Am J Kidney Dis. 2014; 64(5):685-95

85 Kalantar-Zadeh K, Regidor DL, Kovesdy CP, Van Wyck D, Bunnapradist S, Horwich TB, et al. Fluid retention is associated with cardiovascular mortality in patients undergoing long-term hemodialysis. Circulation. 2009; 119(5):671-9.

86 Sinha AD, Agarwal R. Can chronic volume overload be recognized and prevented in hemodialysis patients? Semin Dial. 2009;22(5): $480-2$.

87 Mitsides N, Pietribiasi M, Waniewski J, Brenchley P, Mitra S. Transcapillary refilling rate and its determinants during haemodialysis with standard and high ultrafiltration rates. Am J Nephrol. 2019;50(2):133-43.

88 Agarwal R, Alborzi P, Satyan S, Light RP. Dryweight reduction in hypertensive hemodialysis patients (DRIP): a randomized, controlled trial. Hypertension. 2009;53(3):500-7.

89 Santos SF, Peixoto AJ. Revisiting the dialysate sodium prescription as a tool for better blood pressure and interdialytic weight gain management in hemodialysis patients. Clin J Am Soc Nephrol. 2008;3(2):522-30.

90 Bargman JM, Golper TA. The importance of residual renal function for patients on dialysis. Nephrol Dial Transplant. 2005;20(4):6713.

91 Nongnuch A, Campbell N, Stern E, El-Kateb S, Fuentes L, Davenport A. Increased postdialysis systolic blood pressure is associated with extracellular overhydration in hemodialysis outpatients. Kidney Int. 2015;87(2): 452-7.

92 Sinha AD, Light RP, Agarwal R. Relative plasma volume monitoring during hemodialysis aids the assessment of dry weight. Hypertension. 2010;55(2):305-11.

93 Agarwal R. B-type natriuretic peptide is not a volume marker among patients on hemodialysis. Nephrol Dial Transplant. 2013;28(12): 3082-9.

94 Trezzi M, Torzillo D, Ceriani E, Costantino G, Caruso S, Damavandi PT, et al. Lung ultrasonography for the assessment of rapid extravascular water variation: evidence from hemodialysis patients. Intern Emerg Med. 2013; 8(5):409-15.

95 Davies SJ, Davenport A. The role of bioimpedance and biomarkers in helping to aid clinical decision-making of volume assessments in dialysis patients. Kidney Int. 2014; 86(3):489-96.

96 Dekker MJE, Kooman JP. Fluid status assessment in hemodialysis patients and the association with outcome: review of recent literature. Curr Opin Nephrol Hypertens. 2018; 27(3):188-93.

97 Wizemann V, Wabel P, Chamney P, Zaluska W, Moissl U, Rode C, et al. The mortality risk of overhydration in haemodialysis patients. Nephrol Dial Transplant. 2009;24(5): 1574-9.

98 Tabinor M, Elphick E, Dudson M, Kwok CS, Lambie M, Davies SJ. Bioimpedance-defined overhydration predicts survival in end stage kidney failure (ESKF): systematic review and subgroup meta-analysis. Sci Rep. 2018;8(1): 4441.
99 Mitsides N, McHugh D, Swiecicka A, Mitra R, Brenchley P, Parker GJM, et al. Extracellular resistance is sensitive to tissue sodium status; implications for bioimpedance-derived fluid volume parameters in chronic kidney disease. J Nephrol. 2020;33(1):11927.

100 Tabinor M, Davies SJ. The use of bioimpedance spectroscopy to guide fluid management in patients receiving dialysis. Curr Opin Nephrol Hypertens. 2018;27(6):406-12.

101 Huan-Sheng C, Yeong-Chang C, Ming-Hsing H, Fan-Lieh T, Chu-Cheng L, Tsai-Kun $\mathrm{W}$, et al. Application of bioimpedance spectroscopy in Asian dialysis patients (ABISADIII): a randomized controlled trial for clinical outcomes. Int Urol Nephrol. 2016; 48(11):1897-909.

102 Passauer J, Petrov H, Schleser A, Leicht J, Pucalka K. Evaluation of clinical dry weight assessment in haemodialysis patients using bioimpedance spectroscopy: a cross-sectional study. Nephrol Dial Transplant. 2010; 25(2):545-51.

103 Anand IS, Doan AD, Ma KW, Toth JA, Geyen $\mathrm{KJ}$, Otterness S, et al. Monitoring changes in fluid status with a wireless multisensor monitor: results from the fluid removal during Adherent Renal Monitoring (FARM) Study: fluid monitoring with wireless patient monitor Congest Heart Fail. 2012;18(1):32-6.

104 Santoro A, Mancini E, Paolini F, Spongano M, Zucchelli P. Automatic control of blood volume trends during hemodialysis. ASAIO J. 1994;40(3):M419-22.

105 Basile C, Giordano R, Vernaglione L, Montanaro A, De Maio P, De Padova F, et al. Efficacy and safety of haemodialysis treatment with the Hemocontrol ${ }^{\text {Tx }}$ biofeedback system: a prospective medium-term study. Nephrol Dial Transplant. 2001;16(2):328-34.

106 Barbieri C, Cattinelli I, Neri L, Mari F, Ramos R, Brancaccio D, et al. Development of an artificial intelligence model to guide the management of blood pressure, fluid volume, and dialysis dose in end-stage kidney disease patients: proof of concept and first clinical assessment. Kidney Dis. 2019;5(1): 28-33.

107 Deo RC. Machine learning in medicine. Circulation. 2015;132(20):1920-30.

108 Thakur SS, Abdul SS, Chiu H-YS, Roy RB, Huang P-Y, Malwade S, et al. Artificial-intelligence-based prediction of clinical events among hemodialysis patients using noncontact sensor data. Sensors. 2018;18(9): 2833.

109 Trinh E, Chan CT. The rise, fall, and resurgence of home hemodialysis. Semin Dial. 2017;30(2):174-80.

110 Salani M, Roy S, Fissell WH. Innovations in wearable and implantable artificial kidneys. Am J Kidney Dis. 2018;72(5):745-51.

111 Agre P, Preston GM, Smith BL, Jung JS, Raina S, Moon C, et al. Aquaporin CHIP: the archetypal molecular water channel. Am J Physiol. 1993;265(4):F463-76.
Volume Evaluation in Chronic Kidney Disease and Heart Failure
Kidney Blood Press Res 2021;46:396-410 DOI: $10.1159 / 000515172$ 
112 Leypoldt JK, Henderson LW. The effect of convection on bidirectional peritoneal solute transport: predictions from a distributed model. Ann Biomed Eng. 1992;20(4):46380

113 Mehrotra R, Devuyst O, Davies SJ, Johnson DW. The current state of peritoneal dialysis. J Am Soc Nephrol. 2016;27(11):3238-52.

114 Van Biesen W, Verger C, Heaf J, Vrtovsnik F, Britto ZML, Do J-Y, et al. Evolution over time of volume status and PD-related practice patterns in an incident peritoneal dialysis cohort. Clin J Am Soc Nephrol. 2019; 14(6):882-93.

115 Johnson DW, Dent H, Hawley CM, McDonald SP, Rosman JB, Brown FG, et al. Association of dialysis modality and cardiovascular mortality in incident dialysis patients. Clin J Am Soc Nephrol. 2009;4(10): 1620-8.
116 Tan BK, Yu Z, Fang W, Lin A, Ni Z, Qian J, et al. Longitudinal bioimpedance vector plots add little value to fluid management of peritoneal dialysis patients. Kidney Int 2016;89(2):487-97.

117 Oh K-H, Baek SH, Joo K-W, Kim DK, Kim YS, Kim S, et al. Does routine bioimpedanceguided fluid management provide additional benefit to non-anuric peritoneal dialysis patients? Results from compass clinical trial. Perit Dial Int. 2018;38(2):131-8.

118 Nayak KS, Ronco C, Karopadi AN, Rosner $\mathrm{MH}$. Telemedicine and remote monitoring: supporting the patient on peritoneal dialysis. Perit Dial Int. 2016;36(4):362-6.

119 Martino F, Adıbelli Z, Mason G, Nayak A, Ariyanon W, Rettore E, et al. Home visit program improves technique survival in peritoneal dialysis. Blood Purif. 2014;37(4): 286-90.
120 Nayak A, Karopadi A, Antony S, Sreepada S, Nayak KS. Use of a peritoneal dialysis remote monitoring system in India. Perit Dial Int. 2012;32(2):200-4.

121 Roumelioti M-E, Glew RH, Khitan ZJ, Rondon-Berrios H, Argyropoulos CP, Malhotra $\mathrm{D}$, et al. Fluid balance concepts in medicine: principles and practice. World J Nephrol. 2018;7(1):1-28.

122 Tai R, Ohashi Y, Mizuiri S, Aikawa A, Sakai $\mathrm{K}$. Association between ratio of measured extracellular volume to expected body fluid volume and renal outcomes in patients with chronic kidney disease: a retrospective single-center cohort study. BMC Nephrol. 2014;15:189.

123 Tsai YC, Tsai JC, Chen SC, Chiu YW, Hwang SJ, Hung CC, et al. Association of fluid overload with kidney disease progression in advanced CKD: a Prospective Cohort Study. Am J Kidney Dis. 2014;63(1):68-75. 